\title{
The role of enzyme activation state in limiting carbon assimilation under variable light conditions
}

\author{
Gretchen F. Sassenrath-Cole ${ }^{1}$, Robert W. Pearcy \& Scott Steinmaus \\ Section of Plant Biology, Division of Biological Sciences, Robbins Hall, University of California, Davis CA 95616, \\ California, USA; ${ }^{1}$ Present address: USDA-ARS Crop Simulation Research Unit Department of Plant and Soil \\ Science, P.O. Box 5367, Mississippi State, MS 39762-5367, USA
}

Key words: fructose 1,6-bisphosphatase, lightfleck use efficiency, photosynthetic induction, photosynthetic regulation, ribulose 1,5-bisphosphate carboxylase/oxygenase, soybean

\begin{abstract}
The mechanisms regulating transient photosynthesis by soybean (Glycine max) leaves were examined by comparing photosynthetic rates and carbon reduction cycle enzyme activities under flashing (saturating $1 \mathrm{~s}$ lightflecks separated by low photon flux density (PFD) periods of different durations) and continuous PFD. At the same mean PFD, the mean photosynthetic rates were reduced under flashing as compared to continuous light. However, as the duration of the low PFD period lengthened, the $\mathrm{CO}_{2}$ assimilation attributable to a lightfleck increased. This enhanced lightfleck $\mathrm{CO}_{2}$ assimilation was accounted for by a greater postillumination $\mathrm{CO}_{2}$ fixation occurring after the lightfleck. The induction state of photosynthesis, ribulose-1,5-bisphosphate carboxylase/oxygenase (rubisco), fructose 1,6bisphosphatase (FBPase) and ribulose 5-phosphate kinase (Ru5P kinase) activities all responded similarly and were all lower under flashing as compared to constant PFD of the same integrated mean value. However, the fast phase of induction and FBPase and Ru5P kinase activities were reduced more than were the slow phase of induction and rubisco activity. This was consistent with the role of the former enzymes in the fast induction component that limited RuBP regeneration. Competition for reducing power between carbon metabolism and thioredoxin-mediated enzyme activation may have resulted in lower enzyme activation states and hence lower induction states under flashing than continuous PFD, especially at low lightfleck frequencies (low mean PFD).
\end{abstract}

Abbreviations: FBPase - fructose 1,6-bisphosphatase (EC 3.1.3.11); LUE - lightfleck use efficiency; P-glycerate - 3-phosphoglycerate; PICF - post-illumination $\mathrm{CO}_{2}$ fixation; Ru5P kinase - ribulose 5-phosphate kinase (EC 2.7.1.19); RuBP - ribulose 1,5-bisphosphate; rubisco - ribulose 1,5-bisphosphate carboxylase/oxygenase (EC 4.1.1.39); SBpase - sedoheptulose 1,7-bisphosphatase (EC 3.1.3.37)

\section{Introduction}

Leaves often experience fluctuating PFD regimes because of the pattern of sun and shade cast by other leaves. A significant proportion of the total light received by leaves within canopies is in the form of sunflecks (brief high light periods) (Pearcy et al. 1990). Although most are of very brief duration ( $<$ 1s), longer sunflecks provide most of the daily photon flux. Sunflecks are also clustered, with periods of frequent, short sunflecks separated by periods of low light. Periodic shading limits net carbon uptake of leaves within canopies upon subsequent reillumination at high PFD due to decay of the photosynthetic induction state (Pearcy and Seemann 1990). While this loss of induction reduces carbon assimilation, part of it can be regained by post-illumination $\mathrm{CO}_{2}$ fixation (PICF) in rapidly fluctuating light (Chazdon and Pearcy 1986; Pons and Pearcy 1992). These separate processes work 
in concert to determine the actual rate of carbon fixation occurring during transient light regimes.

The inherent regulatory mechanisms of photosynthetic control that have been examined in detail under steady-state PFD conditions (Heldt et al. 1981; Woodrow and Berry 1988) also contribute to the regulation of photosynthesis under variable light. However, the ways that this regulation influences assimilation rate in fluctuating light may be different from those observed under steady-state conditions. In particular, the kinetics of light-dependent activation and deactivation of photosynthetic enzymes as well as transients in metabolite pools influence the photosynthetic response to PFD level. Single low-to-high PFD transitions have demonstrated three processes that contribute to the induction of photosynthesis. A fast component, important in the first 1-2 min of induction, shows rapid dark deactivation. This component limits the regeneration of RuBP and hence photosynthesis during this time. We have previously shown that the fast induction component is primarily dependent on the stromal fructose 1,6-bisphosphatase (FBPase), and possibly sedoheptulose 1,7-bisphosphatase (SBPase) (Sassenrath-Cole and Pearcy 1992, 1994). The second induction component deactivates slowly in the dark and is dependent on two processes: the level of rubisco activation (Kirschbaum and Pearcy 1988a; Woodrow and Mott 1989), and regulation of stomatal conductance (Kirschbaum and Pearcy 1988a).

Post-illumination $\mathrm{CO}_{2}$ fixation (PICF) is the continued uptake of $\mathrm{CO}_{2}$ after a transition from high to low PFD or darkness. PICF increases the efficiency of utilization of short duration lightflecks (1-10 s), during which it may constitute a majority of the carbon gain (Pearcy 1990). Sharkey et al. (1986) showed that utilization of carbon reduction cycle intermediate pools that are built up during the lightfleck itself are responsible for PICF. The PICF arises due to the continued activity of the first step of carbon reduction, rubisco. The continued reduction of carbon, with the concomitant buildup of product $\mathbf{P}$-glycerate, allows the plant a mechanism to compensate in part for the decrease in photosynthetic activation under low PFD. This simultaneously produces a pool of intermediates available to capture the biochemical energy (in the form of ATP and NADPH) produced during subsequent brief high light periods. This elegant coordination of the electron transport system and carbon reduction cycle allows plants to optimize photosynthetic carbon uptake during the highly variable light environments of natural canopies.
In this study, we examined the relationship between photosynthetic rate, photosynthetic induction state and the activation state of three key light-regulated enzymes of photosynthetic carbon metabolism under constant versus flashing light. We used flashing light to simulate the highly dynamic light regimes of soybean canopies. These studies were designed to provide insight into the mechanisms regulating induction state and lightfleck utilization efficiency and hence carbon gain under transient light conditions.

\section{Materials and methods}

\section{Growth conditions}

Soybeans (Glycine max L. cv. Williams) were grown in 41 pots in a growth chamber at $25 / 17^{\circ} \mathrm{C}$ as previously described (Pons et al. 1992). The plants received 450 $\mu \mathrm{mol}$ photons $\cdot \mathrm{m}^{-2} \cdot \mathrm{s}^{-1}$ for the $14 \mathrm{~h}$ photoperiod. The pots were watered daily with a half strength Hoagland nutrient solution (7.5 $\mathrm{mM} \mathrm{NO}_{3}{ }^{-}$).

\section{Gas exchange measurements}

Several of the youngest fully expanded leaves were selected on each soybean plant for determination of photosynthetic activity. Rates of carbon uptake were made in an open, fast-response system described previously (Kirschbaum and Pearcy 1988b), on a total leaf area of $22 \mathrm{~cm}^{2}$ in a chamber volume of $4 \mathrm{~cm}^{3}$. Leaf temperature was maintained at $25^{\circ} \pm 1{ }^{\circ} \mathrm{C}$ throughout the measurement. Leaves were illuminated at saturating PFD (1800 $\mu \mathrm{mol}$ photons $\left.\cdot \mathrm{m}^{-2} \cdot \mathrm{s}^{-1}\right)$ until steady state rates of photosynthesis were reached. Artificial sunflecks (high PFD lightflecks) and shade periods of various durations were then simulated by an electronic shutter (Uniblitz model 225L, A.W. Vincent Assoc., Rochester, NY). Photosynthetic induction state under flashing light was then determined by following the change in assimilation rate during a subsequent continuous high PFD period. The lightdependence of photosynthesis under continuous illumination was determined by illuminating leaves at different constant sub-saturating PFD levels of the same mean PFD as with flashing light until steady state photosynthetic rates were attained. Photosynthetic induction state was then determined during the subsequent period of continuous illumination at saturating PFD. Flashing light regimes consisted of $1 \mathrm{~s}$ saturating PFD $\left(1800 \mu \mathrm{mol}\right.$ photons $\left.\cdot \mathrm{m}^{-2} \cdot \mathrm{s}^{-1}\right)$ alter- 
nating with $0.5,1,3,9$, or $39 \mathrm{~s}$ low PFD (35 $\mu \mathrm{mol}$ photons $\left.\cdot \mathrm{m}^{-2} \cdot \mathrm{s}^{-1}\right)$. High PFD was provided by a 150 watt quartz-iodide projection lamp, filtered to remove wavelengths outside of the 400 to $700 \mathrm{~nm}$ range. PFD during the shade period was provided by incandescent lamps at $35 \mu \mathrm{mol}$ photons $\cdot \mathrm{m}^{-2} \cdot \mathrm{s}^{-1}$. Intermediate sub-saturating constant PFD levels were attained by filtering the quartz-iodide lamp. The mean assimilation rate under flashing light $\left(A_{f}\right)$ was determined as the average of the photosynthetic rates measured over three consecutive cycles. The assimilation rate due to a lightfleck in flashing light $\left(A_{L}\right)$ was calculated as

$$
A_{L}=\left(A_{f}-A_{b}\right) / d c
$$

where $A_{b}$ was the assimilation rate at constant low PFD, and dc was the duty cycle (fraction of total time that the light was high) as described (Pons and Pearcy 1992). Lightfleck use efficiency (LUE) was calculated as

$$
\text { LUE }=A_{L} /\left(A_{h}-A_{b}\right)
$$

where $A_{h}$ was the assimilation rate at constant saturating illumination.

\section{Determination of enzyme activities}

Leaves for determination of in situ enzyme activation state were illuminated in a rapid freeze quench apparatus (Sharkey et al. 1986). After exposing the leaves to various high/low PFD treatments under constant or flashing light, a leaf disc was isolated from the leaf by rapidly clamping between a hammer and anvil chilled to liquid nitrogen temperatures. The $9 \mathrm{~cm}^{2}$ leaf disc was divided into 3 sections, and stored in liquid nitrogen.

Determination of initial enzyme activity was begun by grinding the frozen leaf sections in liquid nitrogen in a mortar and pestle. The frozen leaf powder was scraped into $1 \mathrm{ml}$ extraction buffer consisting of $100 \mathrm{mM}$ Tricine ( $\mathrm{pH} 8.1), 10 \mathrm{mM} \mathrm{MgCl}, 1$ mM EDTA and $15 \mathrm{mM}$ 2-mercaptoethanol. Extraction buffer for determination of FBPase activity contained in addition $1 \mathrm{mM}$ FBP. After suspending the ground leaf powder in extraction buffer, a $0.1 \mathrm{ml}$ aliquot was removed for determination of $\mathrm{Chl}$ as previously described (Sassenrath-Cole and Pearcy 1992), and the remaining extract centrifuged for $5 \mathrm{~s}$. The assays of enzyme activity were begun immediately by addition of an aliquot of leaf extract to the assay buffer. Rubisco activity was determined by the rate of incorporation of ${ }^{14} \mathrm{CO}_{2}$ into P-glycerate during a $30 \mathrm{~s}$ assay using $50 \mu \mathrm{l}$ leaf extract (Brooks and Portis 1988). FBPase and Ru5P kinase were assayed spectrophotometrically using pyridine nucleotide-linked enzyme assays (Sibley and Anderson 1989) with minor modifications. An SLM Aminco model DW-2000 dual wavelength spectrophotometer at $340 / 410 \mathrm{~nm}$ was used. Changes in pyridine nucleotide levels were calculated using a molar extinction coefficient at $340 \mathrm{~nm}$ of $6.27 \mathrm{M}^{-1} \cdot \mathrm{cm}^{-1}$. FBPase activity was determined in 1 $\mathrm{ml}$ assay buffer in a final volume of $100 \mathrm{mM}$ Tricine (pH 8.1), $20 \mathrm{mM} \mathrm{MgCl}$, 1 mM EDTA, $0.3 \mathrm{mM}$ NADP, $0.6 \mathrm{mM}$ FBP, 0.6 units G6PDH, and 1.2 units PGI, to which was added $0.1 \mathrm{ml}$ leaf extract. The Ru5P kinase assay buffer consisted of $100 \mathrm{mM}$ Tricine (pH 8.1), 20 $\mathrm{mM} \mathrm{MgCl}$, $1 \mathrm{mM}$ EDTA, $0.2 \mathrm{mM}$ NADH, $2.0 \mathrm{mM}$ R5P, $1.0 \mathrm{mM}$ PEP, $1.0 \mathrm{mM}$ ATP, 20 units pyruvate kinase, 30 units lactate dehydrogenase and 2.5 units phosphoriboisomerase, to which $25 \mu 1$ leaf extract was added.

\section{Results}

Response of photosynthetic activity to flashing light

The photosynthetic activity under various regimes of flashing light was determined by altering the time of low light exposure, while holding lightfleck duration constant at $1 \mathrm{~s}$ (Fig. 1). Although the lightflecks were received as square pulses, the photosynthetic response showed significant damping, in part due to a lag in the measuring system but mostly because of the dynamics of photosynthesis. For longer duration low light periods where the response to individual lightflecks could be observed, assimilation exhibited a rapid rise followed by a slow decline due to PICF. A change to constant PFD initiated an induction response that resulted in a return to steady-state assimilation. This required up to $20 \mathrm{~min}$ at the lowest lightfleck frequency (data not shown). The induction of photosynthesis at saturating PFD after preillumination in flashing light displayed a rapid initial increase in activity, followed by a gradual increase over longer time, as has been observed previously for leaves preilluminated in constant light at low PFD (Sassenrath-Cole and Pearcy 1992).

The dependence of photosynthetic activity on incident PFD of constant or variable duration was contrasted by measuring the assimilation rate of leaves at different PFD under either continuous or flashing illumination of the same mean PFD (Fig. 2). The mean assimi- 


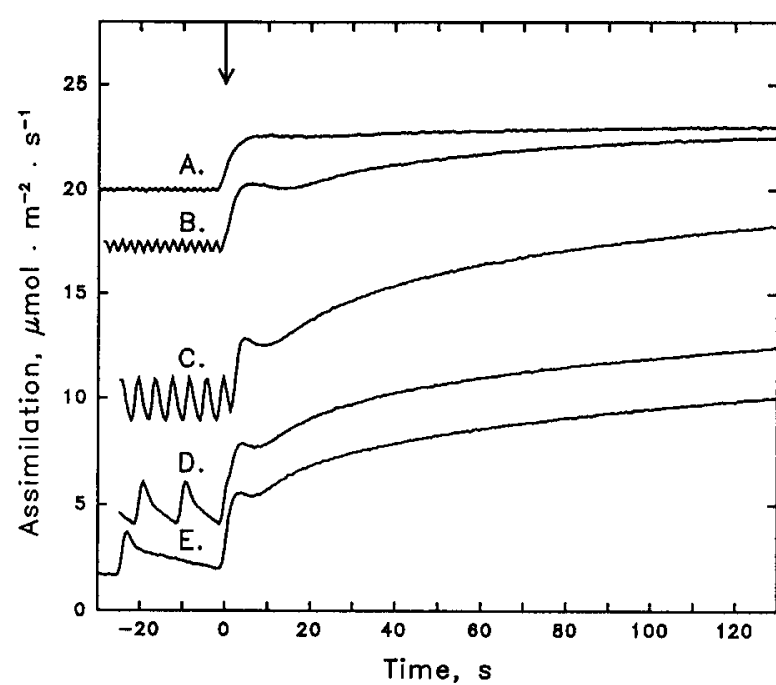

Fig. 1. Photosynthetic activity under flashing light: Photosynthetic activity under flashing light was determined using a fast-response open gas-exchange system. The flashing light alternated between saturating PFD $\left(1800 \mu \mathrm{mol} \cdot \mathrm{m}^{-2} \cdot \mathrm{s}^{-1}\right)$ for $1 \mathrm{~s}$ and sub-saturating PFD $\left(35 \mu \mathrm{mol} \cdot \mathrm{m}^{-2} \cdot \mathrm{s}^{-1}\right)$ for various treatments of A. $0.5 \mathrm{~s} ;$ B. $1 \mathrm{~s}$; C. $3 \mathrm{~s} ;$ D. $9 \mathrm{~s} ;$ or E. $39 \mathrm{~s}$. The photosynthetic induction state during the flashing light treatment was determined by measuring the rate of carbon assimilation during subsequent exposure to continuous saturating PFD begun at time zero (indicated by the arrow). Typical data from a single leaf is presented.

lation rate during the flashing light $\left(\mathrm{A}_{\mathrm{f}}\right)$ was calculated as the mean over three consecutive cycles of lightflecks and shade periods. The assimilation rate due to individual lightflecks $\left(A_{L}\right)$ and the LUE were calculated as described by Pons and Pearcy (1992). Although the leaves received the same mean PFD, the mean photosynthetic rate $\left(A_{f}\right)$ was reduced under flashing illumination. Individual lightfleck assimilation $\left(A_{L}\right)$, however, was much greater than that observed under continuous illumination for the same $1 \mathrm{~s}$ duration. This resulted in a significant increase in LUE as the mean PFD decreased (lightfleck frequency decreased) (Fig. 3). $A_{L}$ was greatest at lowest lightfleck frequencies that also resulted in a low mean PFD, and converged towards the steady-state photosynthetic rate under constant light $\left(\mathrm{A}_{\mathrm{c}}\right)$ as lightfleck frequency increased. Low lightfleck frequency gave a long period of low PFD that allowed for maximum PICF before the next lightfleck, increasing the LUE.

The induction state was determined as the photosynthetic rate after $5 \mathrm{~s}\left(\mathrm{IS}_{5}\right)$ and $120 \mathrm{~s}\left(\mathrm{IS}_{120}\right)$ reillumination at saturating PFD. The relative photosynthetic rate at these two times serve as a measure of the limitations imposed by the fast and slow components of

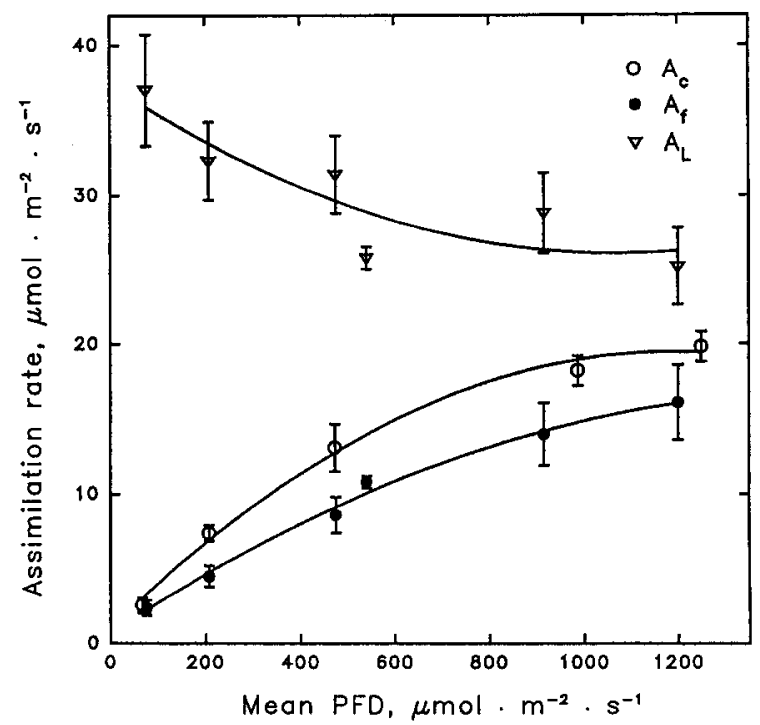

Fig. 2. Photosynthetic activity under flashing and constant PFD: The assimilation rate under constant $\left(A_{\mathfrak{c}}, 0\right)$ and flashing illumination (described in Fig. 1) was measured in an open fast-response gas-exchange system at various mean PFD levels. The mean PFD under flashing illumination was determined as the mean incident PFD over a given time span for the various frequencies of low light exposure. The mean assimilation rate under flashing light $\left(A_{f}, \bullet\right)$ was determined as the average of the photosynthetic rates measured over three consecutive cycles. The assimilation rate due to a lightfleck in flashing light $\left(A_{L}, \Delta\right)$ was calculated from $\left(A_{f}-A_{b}\right) / d c$, where $A_{b}$ was the assimilation rate at constant low PFD, and dc was the duty cycle (fraction of total time that the light was high) as described (Pons and Pearcy 1992). Data are presented from a minimum of 3 separate leaves \pm s.e.

induction, respectively. IS $_{5}$ and IS 120 were lower under flashing light than continuous light of the same mean PFD for intermediate PFD values (Fig. 4), with IS $_{5}$ being significantly lower. At both saturating and the lowest PFD, the differences in induction state between constant and flashing light disappeared. IS $_{5}$ and IS $_{120}$ showed similar declines in activation as duration of low light increased (lightfleck frequency decreased), though the magnitude of the decrease was greater for the fast induction component $\left(\mathrm{IS}_{5}\right)$.

Contribution of the regulatory carbon assimilation enzymes to the reduction in photosynthetic activity under flashing light.

We compared Rubisco, FBPase and Ru5P kinase activities to the rate of photosynthesis under constant and flashing light to elucidate whether down-regulation of these enzymes could explain the observed differences in induction state (Fig. 5). Under flashing illumination, 


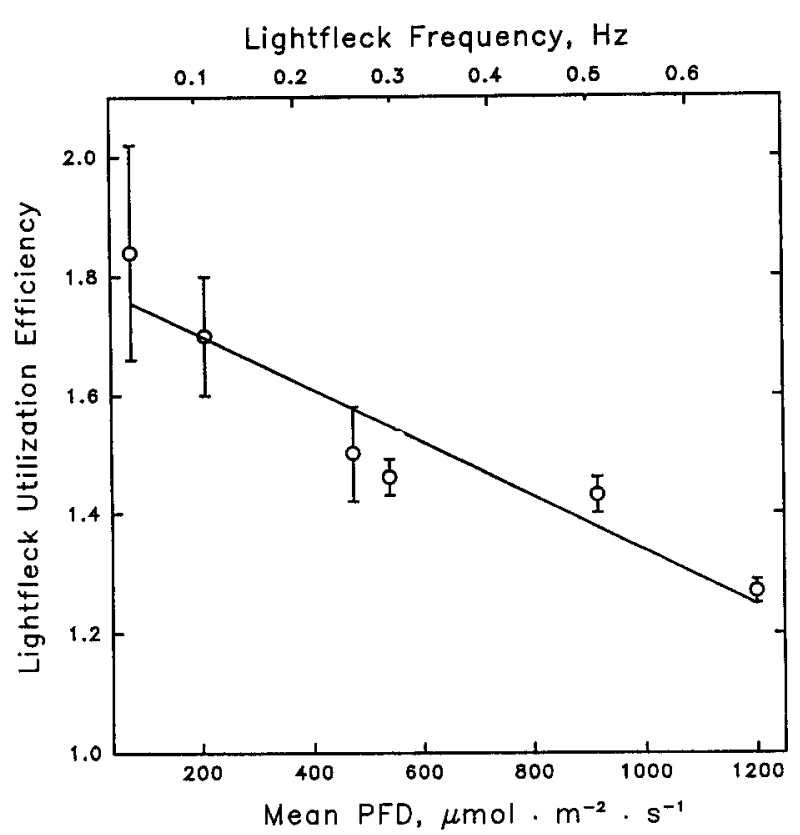

Fig. 3. Dependence of lightfleck utilization efficiency on lightfleck regime: Lightfleck utilization efficiency was determined from the photosynthetic response under flashing light described in Fig. 1, and calculated as $A_{L} /\left(A_{h}-A_{b}\right)$, where $A_{L}$ was the carbon uptake due to the individual lightfleck, as determined in Fig. 2 , and $A_{h}$ and $A_{b}$ were the steady-state photosynthetic rates under continuous high (1800 $\left.\mu \mathrm{mol} \cdot \mathrm{m}^{-2} \cdot \mathrm{s}^{-1}\right)$ or low $\left(35 \mu \mathrm{mol} \cdot \mathrm{m}^{-2} \cdot \mathrm{s}^{-1}\right)$ PFD, respectively.

all enzymatic activities were lower than those observed under constant light. The dependence of rubisco activity on incident mean PFD under flashing light very nearly matched that of photosynthesis. FBPase activity, on the other hand, showed a greater deviation from the light response of photosynthesis in flashing light, with lower levels of activity at mean PFD greater than $500 \mu \mathrm{mol} \cdot \mathrm{m}^{-2} \cdot \mathrm{s}^{-1}$. Ru5P kinase activity also deviated from the photosynthetic curve in flashing light, in that the activity of Ru5P kinase was much less dependent on PFD than was photosynthesis. However, the enzyme activity was still 5-fold greater than that needed to support maximal photosynthetic rates under constant light. FBPase and rubisco exhibited a similar dependence on lightfleck frequency. The greater decay of the fast induction component (Fig. 4) corroborated the greater decrease in activity of FBPase than rubisco (Fig. 5).

The relationship between enzyme capacity measured in vitro as extractable enzyme activity and in situ photosynthetic rate measured in the same leaves is shown in Fig. 6. Rubisco activity showed a nearly identical change with photosynthetic rate under flash-

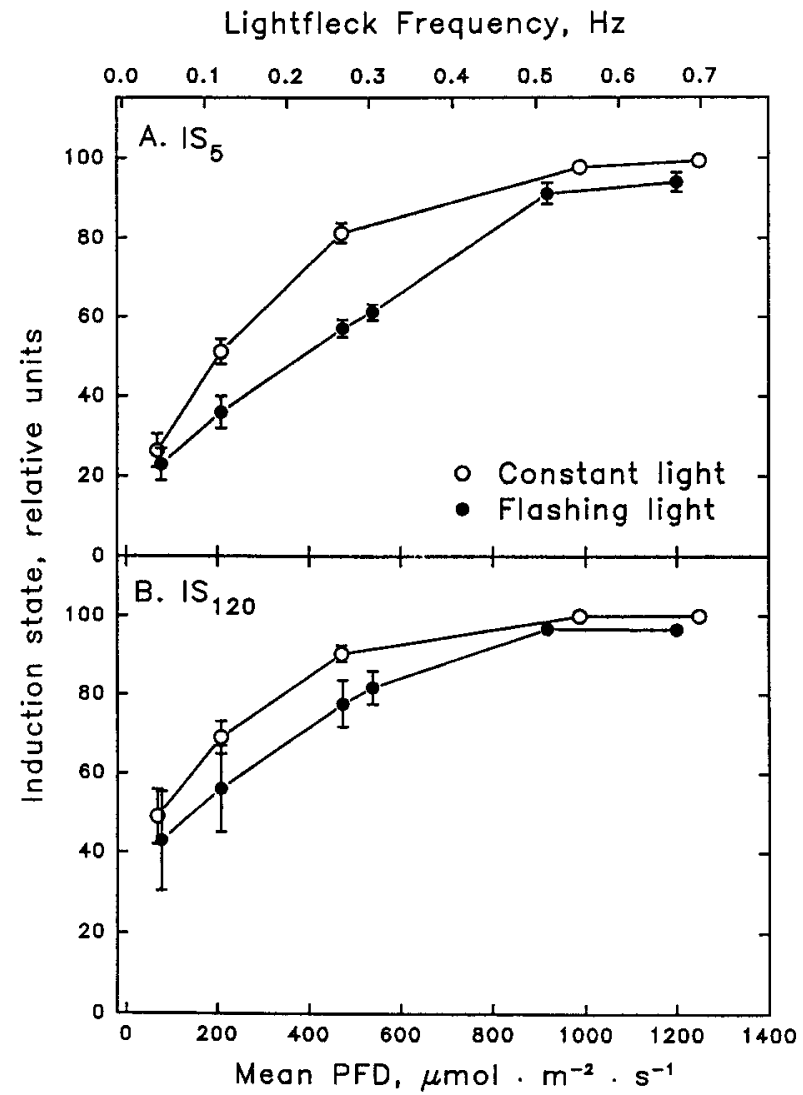

Fig. 4. Induction state of photosynthesis as a function of mean $P F D$ under flashing and constant illumination. The induction state of the photosynthetic apparatus following subsaturating illumination at various regimes of flashing light (described in (Fig. 1) or constant light of the same mean PFD was determined by measuring the assimilation rate during reillumination under continuous saturating PFD. The induction state of the photosynthetic apparatus under flashing $(\bullet)$ light treatments described in Figure 1 or constant (o) light were determined as the assimilation rate after $5 \mathrm{~s}$ (A. IS 5 ) and $120 \mathrm{~s}$ $\left(B . I_{120}\right)$ reillumination at saturating PFD. Flashing light alternated between saturating PFD for $1 \mathrm{~s}$ and low PFD for $0.5,1,3,9$, or 39 s. The mean PFD was determined as the mean incident PFD over a given time span for the various frequencies of low light exposure. Reported values are means \pm s.e. of a minimum of 3 separate leaves.

ing and constant PFD. The activities of FBPase and Ru5P kinase, on the other hand, were significantly reduced under flashing illumination as photosynthetic rate decreased. The slope of the line gives the ratio of enzyme capacity to in situ photosynthetic activity, and hence is an indication of the excess in enzyme activation state. There was only a slight decrease (15\%) in the ratio of rubisco capacity to photosynthetic rate in flashing light. A much more significant decrease in the FBPase (45\%) and Ru5P kinase (65\%) ratios were observed under flashing light than under constant light. 


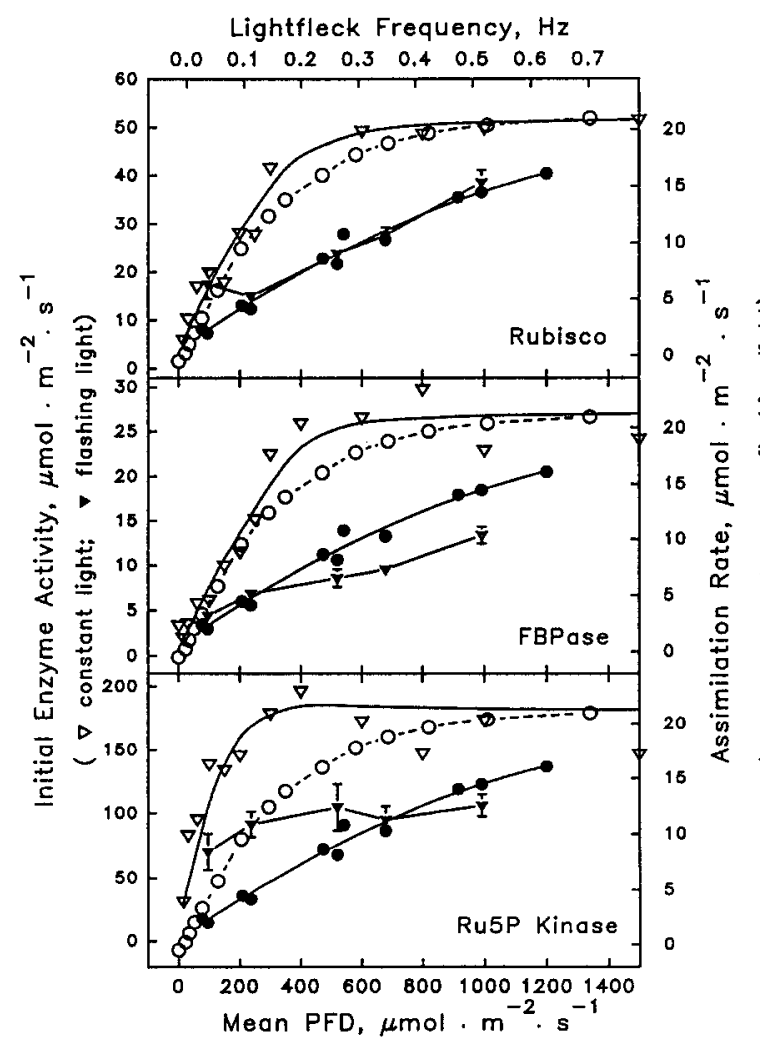

Fig. 5. Photosynthetic and enzymatic activity as a function of $P F D$. Assimilation rate of leaves under continuous (dashed line) or flashing ( $\bullet$, solid line) illumination was determined at various PFD levels. Leaves for enzyme analysis were illuminated under constant $(\Delta)$ or flashing $(\Delta)$ light until steady-state rates of photosynthesis were observed. Flashing light sequences were $1 \mathrm{~s}$ high light, and 1 , $2,3,9$ or $39 \mathrm{~s}$ low light. Mean PFD was determined as in Figure 2. Mean photosynthetic rates $\left(A_{f}\right)$ were calculated over three complete cycles of flashing light exposure. Leaf discs were then isolated in the rapid freeze-quench apparatus and enzyme activities determined as described. The axis for enzyme activity and assimilation rate are adjusted to facilitate comparison of the light response under continuous illumination. Enzymatic activities at all light levels and all treatment conditions were several-fold in excess of those needed to support the observed photosynthetic rates. Values reported for enzyme activities from leaves under flashing light $(\boldsymbol{\Delta})$ are means of a minimum of 3 separate leaves \pm s.e.

\section{Discussion}

Under natural growing conditions, plants typically experience highly variable light conditions due to the pattern of sun and shade. The normal steady-state mechanisms of photosynthetic regulation observed under constant illumination will be different under alternating sun and shade due to the kinetics of lightdependent activation and dark-deactivation of the primary regulatory enzymes of carbon metabolism. Acti-

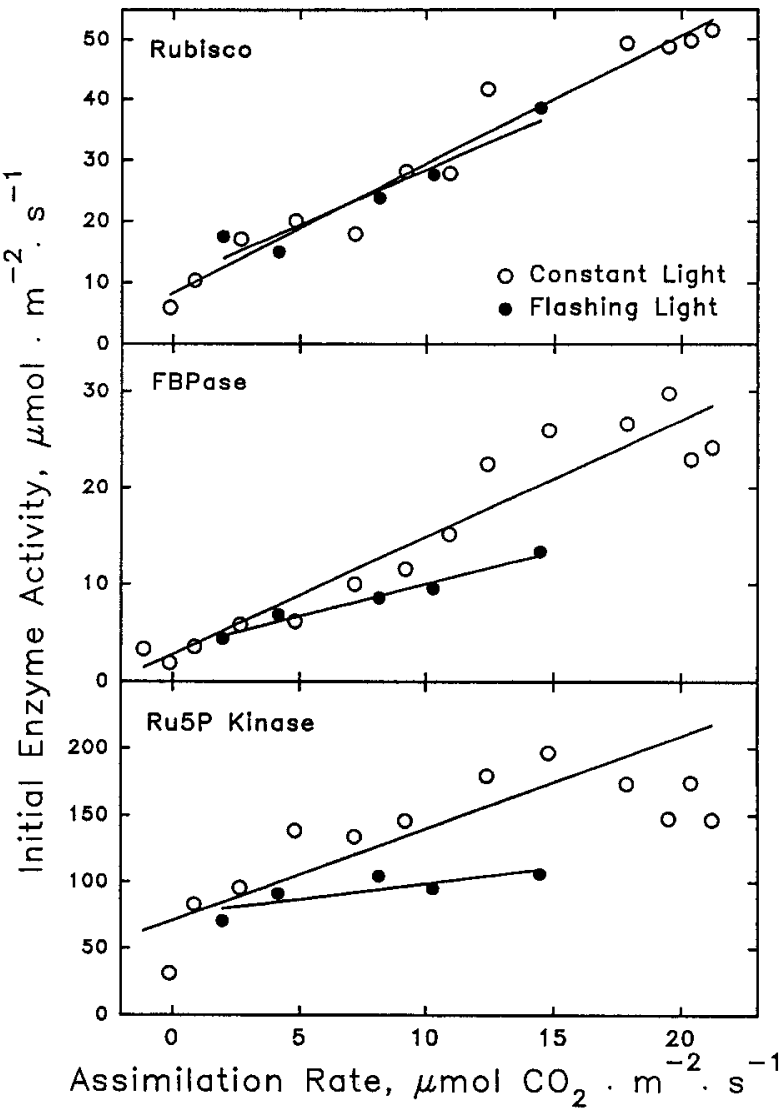

Fig. 6. Enzyme activity versus assimilation rate: Regressions of rubisco, FBPase and RuSP kinase activities against the mean assimilation for leaves illuminated under constant (o) or flashing $(\bullet)$ illumination are derived from data presented in Fig 5. Regression equations are as follows: Rubisco, constant light $(0) \mathrm{y}=8.39+2.17 \mathrm{x}, \mathrm{r}^{2}=$ 0.914 ; flashing light $(\bullet) \mathrm{y}=10.42+1.81 \mathrm{x}, \mathrm{r}^{2}=0.959$; FBPase, constant light $(0) \mathrm{y}=0.14+1.59 \mathrm{x}, \mathrm{r}^{2}=0.956$; flashing light $(\bullet) \mathrm{y}=$ $3.42+0.66 \mathrm{x}, \mathrm{r}^{2}=0.986$; Ru5P kinase, constant light $(0) \mathrm{y}=70.82$ $+6.92 \mathrm{x}, \mathrm{r}^{2}=0.554$; flashing light $(\bullet) \mathrm{y}=74.80+2.40 \mathrm{x}, \mathrm{r}^{2}=0.82 .2$

vation of FBPase occurs via reduction by thioredoxin $f$ (Scheibe 1991), which lowers the $K_{m}$ for the substrate (Mg-FBP complex) such that the enzyme is catalytically competent under cellular conditions (Baier and Latzko 1975, Portis and Heldt 1976). The negative midpoint potential of the FBPase (Ort and Oxborough 1992) results in rapid deactivation of the FBPase upon transfer to light-limiting conditions (Sassenrath-Cole and Pearcy 1994). Activation of rubisco is mediated via rubisco activase, and is also dependent on electron transport by an unknown mechanism (Portis 1992). However, deactivation of rubisco in low light is much slower than deactivation of FBPase (Sassenrath-Cole and Pearcy 1994). This dependence of carbon metab- 
olizing enzymes on activation by electron transport coordinates the steps of photosynthesis and may serve to maintain a balance between the component steps of carbon metabolism as the supply of light varies (Harbinson et al. 1990).

Rubisco and FBPase are regulated by different mechanisms, yet the results show that they are lightregulated in a coordinated fashion. In other words, the basic light response for the two is very similar, and closely matches the light response of photosynthesis. Under flashing light, the FBPase and Ru5P kinase showed relatively greater deactivation than was observed for rubisco (Fig. 5). The decrease in FBPase activity was consistent with the greater loss of activity of the fast induction component (IS 5 ) than slow induction component $\left(\mathrm{IS}_{120}\right)$ as lightfleck frequency decreased (Fig.4). The increase in FBPase activity observed following a brief single low-light transient (<30 s) (Sassenrath-Cole and Pearcy 1994), did not occur with long periods of flashing light exposure (Fig. 5). Rather, there was a significant decrease in FBPase activity under flashing light, even for very short low PFD duration. The decline in enzyme activity as the duration of low PFD exposure increased (lightfleck frequency decreased) indicated an adjustment of enzyme activity to flashing light (Fig. 5). Rubisco, Ru5P kinase and FBPase activities declined in conjunction with photosynthetic activity under flashing and constant light (Fig. 6). However, the capacity of the thioredoxin-activated enzymes, FBPase and RusP kinase, decreased $50 \%$ relative to the in situ photosynthetic activity. While the enzyme capacities were still in excess of those needed to support photosynthesis under constant light, the significant drop in enzyme capacity, particularly of the thioredoxin-mediated enzymes, is intriguing. With exposure to flashing light for long periods of time, there may be sufficient reduction energy to maintain adequate pools of NADPH to fix carbon, but not enough to provide the necessary redox pools to maintain a high redox state in the chloroplasts at low light. Although the activation state of the enzymes determined under conditions of no substrate limitations in vitro may be sufficient to support measured photosynthetic rates, the loss of enzymatic capacity may limit photosynthesis in situ.

Under the flashing and constant light regimes used in this study, the leaves received the same mean PFD, but the temporal distribution of photons was different (Fig. 1). The plants responded to this difference in PFD distribution with a lower mean photosynthetic rate than under constant PFD (Fig. 2). The photosyn- thetic rate was therefore dependent on the pattern of high and low light periods. The maximum assimilation rate achieved during a lightfleck was limited by the decay of photosynthetic induction (Fig. 4), but the total lightfleck assimilation was enhanced by PICF, with a resultant net increase in LUE (Fig. 3) (Pearcy 1990). The PICF became increasingly significant at lower lightfleck frequencies as shown by the calculated individual lightfleck assimilation $\left(A_{L}\right)$ (Fig. 2) and LUE (Fig. 3). Since lightfleck duration was a constant $1 \mathrm{~s}$, the decreasing frequency corresponded to longer intervening low light periods. PICF may depend on the low-light period duration for several reasons. First, at brief low light periods, the succeeding lightfleck may interrupt the PICF. Second, PICF depends on the photosynthetic metabolite pool sizes (Sharkey et al. 1986). Very rapid lightfleck frequencies may allow insufficient time for these pools to build up before the subsequent lightflecks. The minimal rate of electron transport during the low light period is probably sufficient to maintain adequate levels of ATP synthesis for regeneration of RuBP (Sharkey et al. 1986; Groom et al. 1993). This pool of RuBP is utilized after the lightfleck to fix carbon at low light, giving additional $\mathrm{CO}_{2}$ fixation and increasing the pool of P-glycerate for use during the next lightfleck. P-glycerate is rapidly metabolized upon exposure to high light (Sassenrath-Cole et al. 1992, 1994).

In this study, we found an increase in LUE due to PICF, particularly as the duration of low light increased. The mean photosynthetic rate under flashing light, however, was limited by the decay of the induction state. The most important contribution to this decay under flashing light arose due to deactivation of the thioredoxin-activated enzymes, FBPase and RuSP kinase. Maintaining a high level of FBPase activity in particular is difficult and costly for the leaf. The activation state of the FBPase is closely linked with electron transport, as it requires high redox energy and deactivates quickly as the redox state of the chloroplast decreases as light becomes limiting. Due to the negative redox potential of the FBPase (Ort and Oxborough 1992), its reductive activation requires significant redox energy that competes with NADP reduction required for carbon metabolism. The Ru5P kinase, though also redox-activated, maintains the enzyme capacity in much greater excess than the FBPase (Fig. 5). The sensitivity of the thioredoxinactivated enzymes to stromal redox state allows a finetuning of carbon metabolism to external environmental conditions. The hysteretic response of rubisco to acti- 
vation, with a more rapid activation and slower deactivation (Kirschbaum and Pearcy 1988a; Woodrow and Mott 1989; Sassenrath-Cole and Pearcy 1992, 1994), would tend to minimize this potential limitation to carbon uptake during the rapid lightflecks and clustered lightflecks observed within canopies. The results indicate the importance of stromal redox state in regulating carbon assimilation under variable light conditions.

\section{Acknowledgement}

This work was supported by USDA Competitive Grants Office Grant number 91-37100-6670 to RWP.

\section{References}

Baier D and Latzko E (1975) Properties and regulation of C-1fructose-1,6-bisphosphatase from spinach chloroplasts. Biochem Biophys Acta 396: 141-148

Brooks A and Portis Jr AR (1988) Protein-bound ribulose bisphosphate correlates with deactivation of ribulose bisphosphate carboxylase in leaves. Plant Physiol 87: 244-249

Chazdon RL and Pearcy RW (1986) Photosynthetic responses to light variation in rain forest species. II. Carbon gain and light utilization during lightflecks. Oecologia 69: 524-531

Groom QJ Kramer DM and Crofts AR and Ort DR (1993) The nonphotochemical reduction of plastoquinone in leaves. Photosynth Res 36: 205-215

Harbinson J, Genty B and Foyer CH (1990) Relationship between photosynthetic electron transport and stromal enzyme activity in pea leaves. Plant Physiol 94: 545-553

Heldt HW, Laing W, Lorimer GH, Stitt M and Wirtz W (1981) On the regulation of $\mathrm{CO}_{2}$ fixation by light. In: Akoyunoglou $\mathrm{G}$ (ed) Photosynthesis IV. Regulation of Carbon Metabolism, pp 213226. Balaban Internatl Sci Serv, Philadelphia, PA

Kirschbaum MUF and Pearcy RW (1988a) Gas exchange analysis of the relative importance of stomatal and biochemical factors in photosynthetic induction in Alocasia macrorrhiza. Plant Physiol 86: 782-785

Kirschbaum MUF and Pearcy RW (1988b) Gas exchange analysis of the fast phase of photosynthetic induction in Alocasia macrorrhiza. Plant Physiol 87: 818-821
Ort DR and Oxborough K (1992) In situ regulation of chloroplast coupling factor activity. Ann Rev Plant Physiol Plant Mol Biol 43: 269-291

Pearcy, RW (1990) Sunflecks and photosynthesis in plant canopies. Ann Rev Plant Physiol Plant Mol Biol 41: 421-453

Pearcy RW, Roden JS and Gamon JA (1990) Sunfleck dynamics in relation to canopy structure in a soybean (Glycine max (L.) Merr.) canopy. Agric Forest Meteorol 52: 359-372

Pearcy RW and Seemann JR (1990) Photosynthetic induction state of leaves in a soybean canopy in relation to light regulation of ribulose-1,5-bisphosphate carboxylase and stomatal conductance. Plant Physiol 94: 628-633

Pons TL, Pearcy RW and Seemann JR (1992) Photosynthesis in flashing light in soybean leaves grown in different conditions. I. Photosynthetic induction state and regulation of ribulose-1,5bisphosphate carboxylase activity. Plant Cell Environ 15: 569576

Pons TL and Pearcy RW (1992) Photosynthesis in flashing light in soybean leaves grown in different conditions. II. Lightfleck utilization efficiency. Plant Cell Environ 15: 577-584

Portis Jr AR (1992) Regulation of ribulose 1,5-bisphosphate carboxylase/oxygenase activity. Ann Rev Plant Physiol Plant Mol Biol 43: 415-437

Portis Jr AR and Heldt HW (1976) Light-dependent changes of the $\mathrm{Mg}^{2+}$ concentration in the stroma in relation to the $\mathrm{Mg}^{2+}$ dependency of $\mathrm{CO}_{2}$ fixation in intact chloroplasts. Biochim Biophys Acta 449: 434-446

Sassenrath-Cole GF and Pearcy RW (1992) The role of ribulose1,5-bisphosphate regeneration in the induction requirement of photosynthetic $\mathrm{CO}_{2}$ exchange under transient light conditions. Plant Physiol 99: 227-234

Sassenrath-Cole GF and Pearcy RW (1994) Regulation of photosynthetic induction state by the magnitude and duration of low light exposure. Plant Physiol (in press)

Scheibe R (1991) Redox-modulation of chloroplast enzymes. Plant Physiol 96: 1-3

Sharkey TD, Seemann JR and Pearcy RW (1986) Contribution of metabolites of photosynthesis to postillumination $\mathrm{CO}_{2}$ assimilation in response to lightflecks. Plant Physiol 82: 1063-1068

Sibley MH and Anderson LE (1989) Light/dark modulation of enzyme activity in developing barley leaves. Plant Physiol 91: 1620-1624

Woodrow IE and Berry JA (1988) Enzymatic regulation of photosynthetic $\mathrm{CO}_{2}$ fixation in $\mathrm{C}_{3}$ plants. Ann Rev Plant Physiol Plant Mol Biol 39: 533-594

Woodrow IE and Mott KA (1989) Rate limitation of non-steadystate photosynthesis by ribulose-1,5-bisphosphate carboxylase in spinach. Aust J Plant Physiol 16: 487-500 